\title{
A BASE IDE OLÓGICA DO DIREITO PENAL DO INIMIGO (GÜNTER JAKOBS): SOCIEDADE DE RISCO E SEUS EFEITOS NO ESTADO DEMOCRÁTICO DE DIREITO
}

RAMIRO ANZIT GUERRERO 


\title{
A BASE IDEOLÓGICA DO DIREITO PENAL DO INIMIGO (GÜNTER JAKOBS): SOCIEDADE DE RISCO E SEUS EFEITOS NO ESTADO DEMOCRÁTICO DE DIREITO
}

\author{
Ramiro Anzit Guerrero ${ }^{1}$
}

\section{RESUM 0}

O direito penal do inimigo, proposto por Günther J acobs, representa a antítese do direito penal garantista, de cunho liberal, idealizado e desenvolvido a partir da Revolução Francesa. Contudo, para que seja possível analisálo a partir do texto constitucional brasileiro (proposta do presente trabalho) faz-se necessária a compreensão de suas características latentes, o que significa mergulhar a fundo no pensamente de seu artífice, Günther Jacobs.

Palavras-chave: Direito penal do inimigo. Garantismo. Garantias constitucionais. Estado Democrático.

\section{ABSTRACT}

The enemy's criminal law, proposed by Günther Jacobs, represents

1 Pós-Doutor em Direito Penal eGarantias Constitucionais pela Universidade Federal deLaMatanza, Doutor emDireito Penal eCiências PenaispelaUni versidadeDel Sal vador, Mestre em Estudos Estratégicos pela Escola de Guerra Naval Argentina. Ex- Diretor do Doutorado em Ciências J urídicas e Sociais da Universi dade do Museu Social Argentino. Professor Titular de Pratica Forense na Graduação e Professor Titul ar de Criminologia na Especialização em Direito Penal da Universidade del Salvador. Professor da Escola da Magistratura dos Estados do Pará e Paraíba. Consel heiro Editorial da Escola Superior da Magistratura do Rio Grande do Norte / Tribunal de Justiça; Membro do Conselho de Publicações Faculdade de Tecnologia da Amazônia - FAZ. Publicou 14 livros entre eles: Criminología, evolución y análisis (2007); Compendium Criminis: Criminología, Criminalistica y Victimología (2010) Realidades y Perspectivas del Derecho Penal en el Siglo XXI (2011); Derecho Informatico (2011); Derecho Penal y Paradigma Criminológico en América Latina (2012). Membro Instituto de Ciências Penais (Minas Gerais Brasil ). Membro do Instituto de Direito Penal eCriminologia, Ordem dos Advogados da Capital Federal (Argentina) Membro Sociedade Mexicana de Criminologia. Membro Internacional Association for Counterterrorism \& Security Professionals. Membro Association for the Study of Middl e East \& Africa (USA). 
the antithesis of the constitutional guarantees in the traditional criminal law, liberal State, designed and developed from the French Revolution. However, in order to be able to analyze it from the Brazilian constitutional text (proposal of this work) it is necessary to understand their underlying characteristics, which means diving into the comfort of its architect, Günther J acobs.

Keywords: Criminal law of the enemy. Garantism Constitutional guarantees. Democratic State.

\section{DIREITO PE NAL DO INIMIGO}

O direito penal do inimigo, proposto por Günther J acobs, representa a antítese do di reito penal garantista, de cunho liberal, idealizado e desenvolvido a partir da Revolução Francesa. ${ }^{2}$ Contudo, para que seja possível analisálo a partir do texto constitucional brasileiro (proposta do presente trabalho) fazse necessária a compreensão de suas características latentes, o que significa mergulhar a fundo no pensamente de seu artífice, Günther J acobs. ${ }^{3}$

Aliás, da mesma forma que o direito penal do inimigo se

$2 \quad$ Nesse sentido: GOMES, Luiz Flávio. Muñoz Conde e o Direito Penal do inimigo . J us Navigandi, Teresina, ano 9, n. 826, 7 out. 2005. Disponível em: বhttp://jus2.uol.com. br/doutrina/texto.asp?id=7399>. Acesso em: 06 jan. 2009. "Quem sustenta o chamado "Direito penal" do inimigo (que é uma espécie de "direito emergencial"), na verdade, pode ser caracterizado como um grande inimigo do Direito penal garantista, porque ele representa um tipo de Direito penal excepcional, contrário aos princípios liberais acolhidos pelo Estado Constitucional e Democrático de Direito". CAPEZ, Fernando. Curso de Direito Penal. 8 ed. ver. E atual., São Paul o: Saraiva, 2005. "a reprovação não se estabel ece em função da gravidade do crime praticado, mas do caráter do agente, seu estilo de vida, personal idade, antecedentes, conduta social e dos motivos que o levaram à infração penal. Há assim, dentro dessa concepção, uma cul pabi lidade do caráter, cul pabi lidade pela conduta de vida ou cul pabilidade pela decisão devida."

3 Doravante será chamado de Jacobs. 
opõe ao direito penal garantista ${ }^{4}$, há um conflito social vivo entre a modernidade reflexiva e a dialética iluminista. ${ }^{5} \mathrm{~A}$ observância deste confronto é importante para o desenvolvimento deste trabal ho, pois a compreensão do direito penal do inimigo exige, em um primeiro momento, a análise do momento histórico em que surgiu esta concepção do direito penal.

Historicamente sabese que Jacobs, em um seminário realizado em Frankfurt, no ano de 1985, detectou que havia se desenvolvido naAlemanha um direito penal parcial, conferindo-o a denominação de di reito penal do inimigo. ${ }^{6}$ Importanteesclarecer que em um primeiro momento J acobs criticou, de forma severa, este direito penal parcial e instrumentalizador da pessoa humana, para posteriormente empunhar uma tese afirmativa, que legitima e justifica essa linha de pensamento. Esta transição no pensamento

$4 \quad$ Nesse sentido: ARANA, Raul Pariona. El derecho penal "moderno" sobre la necesaria legitimidad de la intervenciones penales. Revista Brasileira de Ciências Criminais, n.68. São Paulo: Revista dos Tribunais, set. - out. 2007, p. 112-139, esp. P.117. "Según la concepción de los professores de Frankfurt: Winfried Hassemer, Wolfgang Naucke y PeterAlexisAlbrecht, anteel cuadro de lege data que presenta el ordenamiento jurídico-penal vigente de la Republica Federal deAlemania, se podría hablar em le ciência del derecho penal clasico y deum derecho penal moderno. Según la concepción de estos profesores, el concepto de derecho penal clasico se asocia al modelo de ordenamiento jurídico desarrollado em el curso de los siglos XVIII y XIX que se apoyo em la filosofia de la ilustración y del idealismo alemán. Por el contrario, el derecho penal moderno habría roto com lãs tradiciones del derecho penal dásico, orientado a la garantia de la libertad del ciudadano. El nuevo derecho penal se desarrollaría com ummédio de manejo social y como uminstrumento de pedagogia social. Sehabría producido um cambio de orientación: del paradigma de la justicia penal hacia el paradigma de la prevención. La orientación a los resultados sería em la fase del derecho penal clásico, en el mejor de los casos, sól o um criterio que compl ementaba la dación correcta de las leyes. Hoy, el objetivo del derecho penal moderno sería alcanzar determinados resultados externos. Se afirma, em suma, queel derecho penal no sería más para el legisl ador ultima ratio, sino, emmedia creciente, prima ratio."

5 ADORNO, T.W \& HORKHEIMER, M. Dialética do Esclarecimento: fragmentos filosóficos. Trad. Guido Antonio de Almeida. Rio de Janeiro: Jorge Zahar, 1997.

6 JACOBS, Günther.Criminalización en El estádio previo de la lesión de um bem jurídico. In: Estudios de derecho penal. Madrid: Civitas, 1997. P.293-324. 
de Jacobs esta intimamente relacionada ao fenômeno da global ização, pois foi a partir da global ização que o direito penal passou a enfrentar uma necessária reestruturação dos sistemas das políticas criminais, na medida em que a criminalidade passaa atentar contra as estruturas do Estado.7

Como afirma Beck foi especialmente nos anos finais do sécul oXX enos primeiros destesécul oXXI, queo mundo passou a assistir a mudanças de tamanha amplitude e profundi dade que acabaram por modificar os padrões até então existentes, sendo que estas alterações vão desde o incremento tecnológico até as rupturas epistemológicas e paradigmáticas em praticamente todos os campos do conhecimento humano. ${ }^{8}$

Essas alterações advindas da globalização, não só esclarecem a transição do pensamento de J acobs como também aquilo que Zaffaroni chama de transformação regressiva da política criminal, na medida em que se passou, sem qual quer solução, do debate de políticas abolicionistas ou reducionistas para a expansão do poder punitivo. ${ }^{9}$

Foi justamentenessecontexto histórico queo direito penal do inimigo se fortal eceu, sendo indi scutível a interseção entreessa linha de pensamente penal e a modernidade reflexiva marcada pelo risco. Nessesentido Prittwitz argumentaquedireito penal do risco

7 MORAES, Vinicius Borges de. Concepçôes jusfilosóficas do direito penal do inimigo: uma analise sobre os fundamentos da teoria de Günther Jacobs. Revista Brasileira de Ciências Criminais, n.74. São Paulo: Revista dos Tribunais, set.-out 2008, p.10-34, esp. P.10. 8 BECK, Francis Rafael. Perspectivas de controle ao crime organizado e critica à flexibilização das garantias. São Paulo: IBCCRIM, 2004. P. 21-22.

9 ZAFFARONI, Eugenio Raul. El enemigo en El derecho penal. 1aㅡ ed.,- 1 a reimp. Buenos Aires: Ediar, 2007. P. 13. 
e direito penal do inimigo não são conceitos independentes um do outro, uma vez que, enquanto o direito penal do risco significa uma mudança no modo de compreender o direito penal e de agir dentro dele, mudança esta resultado de uma época, estrutural e irreversível, o direito penal do inimigo é a conseqüência fatal e que deve ser repudiada de um direito penal do risco que se desenvol veu e continua a se desenvolver na direção errada. ${ }^{10}$

Em outras palavras, o discurso que procura legitimar o direito penal do inimigo ganha eco, não pela racionalidade das premissas que o sustentam, embora se deva admitir que a atual proposta deJ acobsseja decertaforma “coerente" "11, mas simpelo momento histórico em que é proferido, pelas características da sociedade pós-industrial, portanto, derisco emque pretendeser aplicado. É dizer: o direito penal do inimigo, alémderepresentar uma ruptura de paradigmas, representa uma reformulação da compreensão do direito penal, reformulação estruturada no limiar do século XXI. Resta saber, porém, se esta reformul ação éconstitucional mente viável.

\section{SOCIEDADE DE RISCO}

Como já mencionado, o presente se caracteriza por um inquestionável progresso dos conhecimentos humanos e por um domínio das forças naturais que determinou o desenvol vimento

\footnotetext{
$\overline{10}$ PRITTWITZ, Cornelius. O direito penal entre o direito penal do risco e o direito penal do inimigo: tendências atuais entre direito penal e política criminal. Revista Brasileira de Ciências Criminais, n.47. São Paulo: Revista dos Tribunais, mar.-abr.2004, p. 31-45, esp. P.32.

11 Coerente deve ser interpretado como racional mente estruturada.
} 
e o aperfeiçoamento das relações e da vida humana. ${ }^{12}$ Entretanto, este fenômeno, impôs modificações profundas na ciência penal, até porque a sociedade contemporânea passou a enfrentar vários fenômenos, transformando-se em uma sociedade de risco. ${ }^{13}$

Frise-se que a expressão sociedade de risco foi cunhada porque Ülrich Beck apresentou um estudo sobre os riscos, sua definição, seu surgimento sua criação e sua distribuição.

Para Ülrich Beck, o processo de industrialização é indissociável do processo de produção de riscos, uma vez que uma das principais conseqüências do desenvolvimento científico industrial é a exposição dos indivíduos a riscos. Portanto, os riscos acompanham a distribuição dos bens, decorrentes da industrialização e do desenvolvimento de novas tecnologias, devendo ser observado que foram gerados sem que a produção de novos conhecimentos fosse capaz de trazer a certeza de que estes riscos diminuiriam ou seriam passíveis de controle e monitoramento eficazes. ${ }^{14}$ Daí afirmar-se que na sociedade de risco os riscos, enquanto produtos dos excessos da produção industrial, ultrapassariamos limites temporal eterritorial..$^{15}$

Em suma, a expressão sociedade de risco é uma teoria

12 MUÑOZ CONDE, Francisco: Introdución al derecho penal. Montevideo-Buenos Aires: B deF, 2003, PP. 182.

13 BECK, Ülrich. Sociedade del riesgo: hacia uma nueva modernidad (Título original Risikogesellschaft. Auf dem Weg in eine andere Moderne, 1986). Trad. Jorge Navarro, Daniel J imenez e Maria Rosa Borras. Barcelona: Pai dós I bérica, 1998.

14 CASTIEL, L. D. (2001) A Centralidade da Regulação na Sociedade de Risco. Esterisco Home Site, FioCruz. Retirado em 07/01/2009, no World Wide Web: http://www.ensp. fiocruz.br/projetos/esterisco/suor6.htm

15 NAVARRO, Marli B. M. deA. \& Cardoso, TelmaA. deO. (2005). Percepção de Risco

e cognição: reflexão sobre a sociedade de risco. Ciências \& Cognição; Ano 02, Vol.06, nov/2005. 
política sobre as mudanças operadas na estrutura da sociedade industrial e, ao mesmo tempo, sobre o conhecimento da modernidade, quefaz comquea sociedade critique o seu próprio desenvolvimento ${ }^{16}$. Essa autocrítica é alimentada justamente pela reflexão, daí o autor referir-se ao período contemporâneo como o período da modernidade reflexiva.

Ocorre, todavia, que essa crítica constante, al imentada pela reflexão, volta-se para todas as instituições fundamentais, inclusive para a base epistemológica que procura legitimar o direito penal. De acordo com Ülrich Beck "a reflexividade da modernidade produz não somente uma crise de orientação, como al egam os comunitaristas, mas uma crise institucional fundamental e mais extensivamente profunda na sociedade industrial tardia. Todas as instituições fundamentais (como partidos políticos e os sindicatos, mas também os princípios causais da responsabili idade na ciência eno direito, as fronteiras nacionais, a ética da responsabilidade individual, a ordem da família nuclear, e assim por diante) perdem suas bases e sua legitimação histórica. Por isso, a reflexividade da modernidade é equivalente ao prognóstico dos conflitos de valor de difícil resol ução sobre os fundamentos do futuro."17

Nesse cenário, foi natural a busca de novas altemativas para a política criminal vigente, tendo em vista que esta política

$\overline{16}$ MACHADO, Marta Rodriguez deAssis. Sociedade do Risco e Direito Penal: uma avaliação de novas tendèncias politico-criminais. São Paulo : IBCCRIM, 2005 (Monografias/ IBCCRIM; 34), P.31.

17 BECK, Ülrich. A Reinvenção da Política. Em: Giddens, A., Beck, U. \& Lash, S.: (Orgs.). Modernização Reflexiva: politica, tradição e estética na ordem social moderna. (pp.211-212). São Paulo: UNESP. 
criminal passou a ser alvo de constantes questionamentos. Como conseqüência, fruto desta reflexividade, há a expansão do poder punitivo estatal, principalmente porque o avanço tecnológico evidenciado determinou o surgimento denovastécnicas del itivas, técnicas estas que, além de facilitar a atividade criminosa, colocamem risco a própria estrutura do Estado. ${ }^{18}$

Na mesma toada percebe-se que a expansão ${ }^{19}$ do poder punitivo estatal ocorre porque passa a existir, por parte da sociedade influenciada pela mídia eletrônica de massa, um constante fortalecimento das expectativas institucionais - em especial do braço armado Estado -, que determina a modificação do centro de gravidade da norma juŕdico-penal que passa da subjetividade do indivíduo para a subjetividade do sistema.

Como alude Muñoz Conde substitui-se uma orientação individual por uma plural. ${ }^{20}$

\footnotetext{
18 HOY OS, Gustavo Balmaceda. Consideraciones críticas sobre El derecho penal moderno y su legitimidad. Revista Brasileira de Ciências Criminais, n.65. São Paul o: Revista dos Tribunais, mar.-abr.2007, p. 52-76, esp. P.53-54.

19 Nessesentido: PRITTWITZ, Cornelius. O direito penal entre o direito penal do risco e o direito penal do inimigo: tendências atuais entre direito penal e política criminal. Revista Brasileira de Ciências Criminais, n.47. São Paulo: Revista dos Tribunais, mar.-abr.2004, p. 31 45, esp. P.38/39." Como é a realidade deste direito penal do risco? O que surgiu foi um direito penal do risco que, longe de qual quer ambição de permanecer fragmentário, sofreu uma mutação para um direito penal expansivo. Isto não é necessariamente assim em teoria, mas empiricamente comprovável. A insinuação de tridimensional idade etimol ogicamentepróxima eintencional obtida com o conceito expansão caracteriza do que se trata: de admitir novos candidatos no círculo dos direitos (como o meio ambiente, a saúde da população e o mercado de capitais), de deslocar mais para frente a fronteira entre comportamentos puníveis e não puníveis - deslocamento este considerado em geral, um pouco precipitadamente como um avanço na proteção exigida pelo direito penal - e finalmente em terceiro lugar de reduzir as exigências de censurabilidade, redução esta que se expressa na mudança de paradigmas, transformando lesão aos bens jurídicos em perigo aos bens jurídicos.

20 MUÑOZ CONDE, Francisco. Direito Penal e controle social. Trad. Cintia Toledo Miranda Chaves. Rio de J aneiro: Forense, 2005. P. 13.
} 
A partir deste contexto histórico ${ }^{21}$ e social, podese perceber, nitidamente, que a sociedade de risco propicia o ambiente favorável para o desenvolvimento do direito penal do inimigo, pensamento penal que projeta efeitos não apenas na dogmática penal material, mas também no campo do processo penal, na medida em que propõe a flexibilização de determinadas garantias individuais deíndole processual.

Nesse tocante é perfeita a col ocação proposta por Busato quando argumenta que e as dificuldades contemporâneas de convívio com o risco geram uma atitude de identificação da alteridade, da diferença, com o risco, devendo o inimigo personificar o risco de fonte desconhecida. ${ }^{22}$

Contudo, não obstante se apresente o risco como a característica principal da sociedade pós-moderna, deve-se assinal ar que esta não é a única característica desta sociedade. Pontual a lição de Arana no sentido de que a principal característica de nossa sociedade é a complexidade das relações sociaisedos processos produtivos, complexidadequeincrementa

\footnotetext{
21 Não há como negar que os atentados de 11 de setembro também contri buíram para o desenvolvimento do direito penal do inimigo. Nesse sentido: NUÑEZ PAZ, Miguel Ángel. Dogmática Penal y política criminal frente a la reforma penal. Revista Brasileira de Ciências Criminais, n.61. São Paulo: Revista dos Tribunais, jul. - ago. 2006, p. 9-43, esp. P.29. “ La cuéstion há cobrado uma minuciosidad teórica bastante importante, que se há visto acentuada incluso a partir de 11 de septiembre de 2001 y que seguro se dispara a partir de la nueva matanza atroz perpetrada em los trenes madrileños del reciente 11 de marzo de 2004. Los países occi dentales se encuentram indefensos siendo víctimas de los mayores atentados terroristas de la historia; Ilegando a parecer que tales barbáries masivas pudieran ser la gota que col mara el vaso permitiendo justificar el abandono de todo principio sostenido hasta el momento, tanto relativo a los derechos humanos, como al derecho penal o al derecho internacinal."

22 BUSATO, Paulo César. Quem é o inimigo, quem é você?. Revista Brasileira de Ciências Criminais, n.66. São Paulo: Revista dos Tribunais, mai. - jun. 2007, p. 112-139, esp. P.114-115.
} 
a insegurança social..$^{23}$

De qual quer forma, a verdade é que o aumento crescente da insegurança nas relações sociais, facilitou, sobremaneira, o arquétipo penal atual mente difundido por J acobs, denominado direito penal do inimigo.

\section{A BASE IDEOLÓgICA DO DIREITO PENAL DO INIMIGO}

A base ideológica do pensamento penal sustentado por Jacobs estrutura-se a partir de dois componentes. O primeiro componentelastreiarse na função da pena. O segundo relaciona se ao conceito de pessoa atribuído pelo autor.

Nessa perspectiva Jacobs considera a prevenção geral positiva como única função da pena criminal. ${ }^{24}$

Significa dizer que tal função concentra as finalidades de intimidação, correção, neutralização e retribuição, sendo que o principal objetivo da pena passa a ser a estabilidade das expectativas de comportamento dos indivíduos por meio do exercício da confiança no direito para a mera estabilização da ordem normativa e, assim, da identidade social.$^{25}$

Nesse viés, há uma nítida instrumentalização do

$23 \quad$ ARANA, Raul Pariona. El derecho penal "moderno" sobrela necesaria legitimidad de la intervenciones penales. Revista Brasileira de Ciências Criminais, n.68. São Paulo: Revista dos Tribunais, set. - out. 2007, p. 315-371, esp. P.347.

24 JACOBS, Günther. Derecho penal:parte general. 2. Ed. Tradução deJ oaquim Cuello Contreras y J ose Luis Serrano Gonzáles de Murrillo. Madrid: Marcial Pons, 1997. P.13.

25 NEUMANN. Ulfrid. Direito Penal do Inimigo Tradução Antonio Martin Revista Brasileira de Ciências Criminais, n.68. São Paulo: Revista dos Tribunais, nov. - dez. 2007, p. 156-177, esp. P.165-166. 
indivíduo, da pessoa, por parte do sistema, ${ }^{26}$ ou como adverte Ferrajoli, na doutrina da prevenção geral, através da ameaça penal derivada da lé, utiliza-se um homem considerado um indivíduo real como um meio para um fim ${ }^{27}$, como se o homem não fosse um fim em si mesmo.

Portanto, o escopo da pena é a comprovação inequívoca da vigência da norma, sem que isto signifique um retorno à teoria absol uta da pena, não obstantea pena passe, na concepção proposta por Jacobs, a encerrar uma justificativa que deriva de si mesma. E não representa um retomo à teoria absoluta da pena porquanto esta não se esgota em si mesma, na medida em que visa a estabilidade social. ${ }^{28}$

Esta afirmação é feita porque para Jacobs o direito penal está orientado a garantir a identidade normativa, a garantir a constituição da sociedade ${ }^{29}$ pois esta só existe quando e na medida em que existem nomas reais. Como conseqüência, a condição para o indivíduo ser considerado pessoa esta

\footnotetext{
$26 \quad$ Nessesentido BARATTA. Integracion-prevención: uma nueva fundamentación dela pena dentro de la teoria sistêmica. Doctrina penal: teoria y prática em lãs ciências penales, año 8, númeors 29 a 32. Buenos Aires: Ediciones Depalma, 1985. P. 22. “ Emespecial, el sujeto em 1a incriminación de responsabilidad penal deja de ser el fin de la intervención institucional, para convertirse en El soporte sicofísico de una acción simbólica, cuyos fines están fuera de El y de la cual constituye únicamente um instrumento. Parece que, aunque com expresiones y lenguaje bien diferentes y mas abstractos, la teoria sistêmica replantea la figura del "chivo expiatorio", de la cual se sirve la teoria psicoanalítica del delito y de la pena para mostrar el componente irracional de los sistemas punitivos."

27 FERRAJ OLI, Luigi. Direito erazão: teoria do garantismo penal. São Paulo : Editora Revista dos Tribunais, 2002, P.225.

28 BENEDETTI, Juliana Cardoso. Raízes sociológicas do funcionalismo penal. Revista Brasileira de Ciências Criminais, n.70. São Paulo: Revista dos Tribunais, jul. - ago. 2008, p. 9-47, esp. P.38.

29 JACOBS, Günther. Sociedade, norma e pessoa: teoria de umdireito penal funcional. Barueri: Manole, 2003. P.1.
} 
relacionada com o momento em que esse indivíduo passa a ser portador de funções, tendo em vista que a pessoa não atua conforme um plano individual de satisfação ou de insatisfação, mas sim conforme umesquema de dever. ${ }^{30}$

Nessaformadecompreensão aspessoasnãoseconfundem comos indivíduos, sendo consi deradas pessoas somente aquel as que se submetem a deveres de um determinado grupo social eàs quais se possa impor uma definição a partir do esquema/dever espaço-livre ${ }^{31}$

Logo, o indivíduo é considerado pessoa a partir e enquanto bem desempenhar seu papel social, sendo que a pena serve apenas para demonstrar ao infrator que a norma continua em vigor, objetivando a manutenção da estabilidade social . $^{32}$

É esse desprezo em relação a dimensão humana do indivíduo que justifica o direito penal do inimigo. Ora, como bem aduz Benedetti, se a pessoa se define simplesmente por desempenhar ou não o seu papel social, deixa de assim ser consi derada quando não corresponde a tais expectativas. ${ }^{33}$

Winfried Hassemer, por sua vez, "observa que a ideia

30 BOZZA, Fábio daSilva. A nálisecritica da prevenção geral positiva no funcionalismo sistêmico de Günther J acobs. Revista Brasileira de Ciências Criminais, n.70. São Paulo: Revista dos Tribunais, set. - out. 2007, p. 41-69, esp. P.49.

31 TAVARES, Juarez. Teoria do I njusto Penal. $2^{\underline{a}}$ edição. rev. e ampl. Belo Horizonte: Del Rey 2002. P. 65.

32 JACOBS, Günther. Sobre la teoria de la pena. Traducción de Manuel Cancio Melliá. Centro de Investigaciones de Derecho Penal y Filosofia del Derecho de La Universidad Externado de Colombia, 2002, p. 18.

33 BENEDETTI, J uliana Cardoso. Raízes sociológi cas do funcionalismo penal. Revista Brasileira de Ciências Criminais, n.3. São Paulo: Revista dos Tribunais, jul. - ago. 2008, p. 9-47, esp. P.38. Nesse sentido: JACOBS, Günther. Sobre la normativización de la dogmática jurídicopenal. Madrid: Civitas, 2005ạ " a pessoa degenera ate converter-se em um mero postulado, eem seu lugar aparece o indi víduo cognitivamente considerado , com o que emerge o inimigo." 
de prevenção desprendeu-se de seu sabor terapêutico, social ou individual" para se estruturar como um instrumento de intervenção na luta contra a criminalidade. Sob essa ótica, "o del inqüentetendea converter-se numini migo, e o direito Penal, emumdireito Penal para inimigos". ${ }^{34}$

Acrescentese, também, que para J acobs pessoas não são definidas primeiramente por direitos, mas sim por deveres, ou seja, é considerada pessoa o indivíduo que cumprir com os próprios deveres, ao passo que os demais, aqueles que não cumprem com os próprios deveres, perdem este status. Estes últimos passam a ser considerados não-pessoas e consequentemente passam a estar sujeitos a intervenções ilimitadas, na medida em que são inimigos. ${ }^{35}$

Por conseguinte este inimigo deixa de ser um sujeito de direitos, passando a ser objeto, razão de não se reconhecer, em favor dele, a necessidade de um processo penal legal, mas sim um procedi mento de guerra. ${ }^{36}$

Por tal motivo, denota-se que o direito penal do inimigo produz efeitos não apenas na dogmática penal material - dentre eles a já citada inflação legislativa - mas também no campo do processo penal. São exatamente estes efeitos que serão analisados no próximo tópico.

\footnotetext{
$34 \quad$ NAUCK, Wolfgang, HASSEMER, Winfried, LÜDERSSEN, Klaus. Principales problemas de la prevención General. Trad. Gustavo Eduardo Aboso. Montevideo - BuenosAires : B deF, 2004, p. 25.

35 NEUMANN. Ulfrid. Direito Penal do Inimigo. Tradução Antonio Martin Revista Brasileira de Ciências Criminais, n.69. São Paulo: Revista dos Tribunais, nov. - dez. 2007, p. 156-177, esp. P.171-172.

36 AMARAL, Cláudio Prado do. Bases Teóricas da Ciência Penal Contemporânea: dogmática, missão do direito penal e política criminal na sociedade de risco. São Paulo: IBCCRIM, 2007 (Monografias IBCCRIM; 44). P. 126.
} 


\section{OS EFEITOS DO DIREITO PE NAL DO INIMIGO}

Um dos efeitos mais marcantes do direito penal do inimigo na dogmática penal reside na clara desmistificação do concei to debemjurídico. Como sal ientado anteriormente, a pena paraJ acobs serve apenas para demonstrar a vigência da norma, razão pela qual, segundo ele, o direito penal visa a proteção da vigência de normas e não de bens jurídicos.

Aqui, deve ser compreendido que o direito penal do inimigo preconiza como função do direito penal, por via reflexa, a manutenção da sociedade, pois éerigido como escopo deevitar a destruição do ordenamento jurídico e como conseqüência oblíqua, segundo o viés funcional ista sistêmico, a manutenção da própria sociedade. ${ }^{37}$

Este objetivo também é observado por Peñarenda Ramos, segundo o qual "na concepção de J acobs, o direito penal obtém sua legitimação material de sua necessidade para garantir a vigência das expectativas normativas essenciais (aquelas de que depende a própria configuração ou identidade da sociedade) di ante das condutas queexpressamuma regra de comportamento incompatível com a noma correspondente e colocam nesta, portanto, uma orientação como modelo geral de orientação no contrato social." ${ }^{38}$

37 MORAES, Vinicius Borges de. Concepções jusfilosóficas do direito penal do inimigo: uma analise sobre os fundamentos da teoria de Günther Jacobs. Revista Brasilerra de Ciências Criminais, n.74. São Paulo: Revista dos Tribunais, set.-out. 2008, p.10-34, esp. p.10. 38 PEÑARENDA RAMOS, Enrique et al. Um novo sistema do direito penal. Considerações sobre a teoria de Günther Jacobs. Trad. André Luís Callegari e Nereu José Giacomolli. Barueri: Manole, 2003. 
Resta claro, portanto, que paraJ acobs a função do direito penal se confunde com a função da pena, ambos existindo para demonstrar a vigência da norma ${ }^{39}$ Por óbvio, então, que o “bemjunídico penal passa a ser a validez fática das normas, que garantem que se possa esperar respeito aos bens, às funções e a paz juńdica." 40

Logo, não se incriminamapenas fatos propriamente ditos e, sim, condutas cuja relevância reside principal mente em seu conteúdo simbólico. ${ }^{41}$

Além de desmistificar a importância do conceito de bem jurídico, o direito penal do inimigo, aproveitando-se dos questionamentos formulados pela sociedade do risco, procura desmaterializálo o que consiste no seu distanciamento da objetividade natural, para focar a tutela de bens universais ou coletivos de perfis cada vez mais abstratos, o que demanda a criação de tios penais formais e de perigo. ${ }^{42}$

Aliás, Santana Veja, compreendendo bem o momento histórico vivido, e analisando os reflexos da modernidade reflexiva no direito penal, adverte que a admissão resignada de que se vive em uma sociedade de risco está a conduzir uma

\footnotetext{
39 BENEDETTI, Juliana Cardoso. Raízes sociológicas do funcionalismo penal. Revista Brasileira de Ciências Criminais, n.73. São Paulo: Revista dos Tribunais, jul. - ago. 2008, p. 9-47, esp. P.38.

40 JACOBS, Günther. Derecho penal:parte general. 2. Ed. Tradução deJ oaquim Cuello Contreras y J ose Luis Serrano Gonzáles de Murrillo. Madrid: Marcial Pons, 1997. P.58.

41 AMARAL, Cláudio Prado do. Bases Teóricas da Ciência Penal Contemporânea: dogmática, missão do direito penal e política criminal na sociedade de risco. São Paulo: IBCCRIM, 2007 (Monografias IBCCRIM; 44). P. 129.

42 MACHADO, Marta Rodriguez deAssis. Sociedade do Risco e Direito Penal: uma avaliação de novas tendèncias político-criminais. São Paulo : IBCCRIM, 2005 (Monografias' IBCCRIM; 34), P.107.
} 
aceitação irrefletida de bens-jurídicos penais coletivos o que vem acompanhado de um adiantamento das barreiras de intervenção do direito penal por meio de erigir o conceito de perigo como fonte, quase única, das infrações penais contra os mesmos. ${ }^{43}$ Em outras palavras, "a puni bilidade avança para o âmbito da preparação, e a pena se dirige para os fatos futuros, não para os fatos já cometidos." 44

Outro efeito inerente a esta linha de pensamento penal resi denaexpansão do di reito penal , expansão estanão relacionada a inflação legislativa denominada expansão extensiva, mas sim intensiva, qual seja: no sentido de que a Política Criminal modulada pel o funcional ismo sistêmico concentra esforços para incrementar a puni ção dos crimes. ${ }^{45}$

Decorre desta postura, acrescida ao efeito anteriormente mencionado - elaboração de tipos penais de perigo abstrato - que o legislador, apesar de antecipar o momento punitivo, lançando mão de tipos penais de perigo abstrato, não reduz

43 SANTANA VEGA, Dulce Maria. La protección penal de los biens jurídicos colectivos. Madrid: Dikinson, 2000, P.103.

44 JACOBS, Günther. Derecho penal del enemigo. Tradução de Cancio Meliá.Madrid: Civitas, 2003, P.40.

45 DÍEZ RIPOLLÉS, J osé Luis: De la sociedad del riesgo a la seguridad ciudadana: um debate desenfocado, em Revista Electrónica de Ciencia Penal y Criminología, 09/01/2009, disponibleemHTTP://crimi net. urg.es/recpc, PP.13-14. I dêntica éa observação de PRITTWITZ, Comelius. O direito penal entre o direito penal do risco e o direito penal do inimigo: tendências atuais entre di reito penal e política criminal. Revista Brasileira de Ciências Criminais, n.47. São Paulo: Revista dos Tribunais, mar.-abr.2004, p. 31-45, esp. P.41-42. “Direito Penal do Inimigo é um direito penal por meio do qual o Estado confronta não os seus cidadãos, mas seus inimigos. Em que isso se faz visível? Primeiramente, tomando-se a lei concretamente- o Código Penal e a legisl ação processual penal, o que se vê é que, onde se trata da punição de inimigos, se pune antes e de forma mais rígi da; o ponto de vista do di reito material a liberdade do cidadão de agir e (principal mente) de pensar érestringida; ao mesmo tempo, subtraem-sedi reitos processuais ao inimigo. 
proporcionalmente a pena destes novos delitos quando comparada a pena dos delitos materiais ou formais com escopo semel hante. ${ }^{46}$

Nessa perspectiva constata-seoutro efeito difundido pelo direito penal do ini migo queéa passagem dal egislação do direito penal para a legislação da luta para combater determinado tipo de del inqüência, ${ }^{47}$ o que também demonstra a intenção de tratar o delinqüente como inimigo.

Essa perspectiva, até certo ponto desumanizadora, é reconhecida pelo próprio Jacobs na medida em que afirma que "há outras muitas regras do Direito Penal que permitem apreciar que naquel es casos em que a expectativa de um comportamento pessoal édefraudada demaneira duradoura di minui adisposição a tratar o delinqüente como pessoa. Assim, por exemplo, o legislador (para permanecer primeiro no âmbito do direito penal material) está passando a uma legislação - denominada abertamente deste modo - de luta, por exemplo, no âmbito da criminalidade econômica, do terrorismo, da criminalidade organizada, no caso de delitos sexuais e outras infrações perigosas." ${ }^{48}$

\footnotetext{
$46 \quad$ Nessesenso: JACOBS, Günther. La ciência del derecho penal antelas exigências del presente. Revista Peruana de Ciências Penales. Edición especial sobreel Código Penal- Peruano. Lima, año VII-VIII, n. 12. Jacobs aporta como ejemplo "que la pena para el cabecilla de uma organización terrorista es igual a la del autor de um tentativa de asesinato, cuando la pena de la tentativa de este sobrepasa de manera ostensible em la mayoría de los casos a qual quiera prevista para los de itos de asociaciones terroristas."

$47 \quad$ NÚÑEZ PAZ, Miguel Ángel. Dogmática penal y política criminal frentea la reforma penal. Revista Brasileira de Ciências Criminais, n.61. São Paul o: Revista dos Tribunais, jul. ago. 2006, p. 9-43, esp. P.31.

48 JACOBS, Günther. Derecho penal del enemigo. Tradução de Cancio Meliá.Madrid: Civitas, 2003, P.38-39.
}

Revista Esmat, Pal mas, Ano 5, oㅜ 5, pag. 191 a 217 - janjjun 2013 
Como fossem insuficientes todos estes efeitos projetados nadogmática penal material, o direito penal do ini migo preconiza a inda a supressão de determinadas garantias individuais como a incomunicabilidade do indiciado e a banal ização da prisão de natureza cautelar.

Deinteressantepode-seressal tar queJ acobs inumeraestas características para demonstrar que sua teoria, o funcionalismo sistêmico, trata de uma tendência aplicada há muitos anos, razão pela qual para ele "um direito penal do inimigo, claramente delimitado, émenos perigoso, desde a perspectiva do Estado de Direito, que entrelaçar todo o direito penal com fragmentos de regulações próprias do direito penal do inimigo." 49

De forma sintética observou-se que o direito penal do inimigo desenvolveu-se em um momento histórico especifico, marcado por constantes questionamentos sociais, o que determinou a necessidade de respostas por parte do estado, em especial de sua política criminal. Estas respostas, em regra sugeridas previamente pela mídia de massa, culminaram coma di fusão do ideário funcional ista sistêmico segundo o qual a pena serve para demonstrar a vigência da norma e o individuo só é considerado pessoa, enquanto cumprir seu papel social .

Os efeitos dessa realidade "absoluta", porém, irrefletida, no campo penal são: a) o amplo adiantamento da puni bilidade, pois o queé punido éo fato que está por acontecer (fundamento prospectivo), e não o fato cometido (considerações sobre uma

49 JACOBS, Günther. Derecho penal del enemigo. Tradução de Cancio Meliá.Madrid: Civitas, 2003, P.49-50.

Revista Esmat, Pal mas, Ano 5, № 5, pag. 191 a 217 - jan/jun 2013 
normal orientação retrospectiva); b) o incremento das penas; c) o relaxamento de determinadas garantias individuais.

Estes efeitos produzem, ainda, duas características que, embora relacionadas, se diferenciam: Primeira: muito mais do que uma mera anteci pação do momento punitivo, observa-seque não se incriminam fatos, e, sim, condutas cuja relevância reside principal mente em seu conteúdo simbólico. Segunda: a técnica da redação dessas infrações é peculiar, principalmente porque o legisl ador se vale de termos ambíguos, vagos, imprecisos, de difícil compreensão para o destinatário da norma. ${ }^{50}$

\section{CONCLUSÃO}

Não há como negar que a sociedade pós-moderna apresenta características pecul iares, destacando-se o risco como uma destas características.

Contudo, aceitar esta evidência, não significa coadunar com o ideário penal do terror que rompe com as barreiras antropocêntricas impostas ao braço armado do Estado. Até porque, a partir do princípio da dignidade da pessoa humana pode-se afirmar que o homem jamais pode ser considerado meio, seja ele etiquetado de terrorista, traficante, homicida ou membro do crime organizado. Logo, este homem chamado de inimigo no ideário proposto por Jacobs, que não se sabe quem é, ou

$50 \quad$ AMARAL, Cláudio Prado do. Bases Teóricas da Ciência Penal Contemporânea: dogmática, missão do direito penal e política criminal na sociedade de risco. São Paulo: IBCCRIM, 2007 (Monografias IBCCRIM; 44). p. 128. 
quem pode vir a ser, depende da ideol ogia dominante, continua a ser o fim do próprio Estado, que só se justifica, nas palavras de Bobbio, enquanto meio ou instrumento que possa tutelar o homem, possibil itando sua emanci pação enquanto ser humano. ${ }^{51}$

E a compreensão de que o ser humano, seja ele quem for, não pode ser instrumentalizado pelo Estado, representa observar que o risco, por si só, não é hábil a justificar a expansão desmedida do direito penal vivenciada na prática não só pela inflação legislativa, mas também pelo aumento desproporcional das penas.

A simples constatação de que a sociedade modema é uma sociedade de riscos, não é suficiente para justificar que o di reito penal deixe deser aúl timaforma de ingerência do Estado na liberdade dos indivíduos, até porque, enquanto o Estado Democrático de Direito existir será o direito penal sua última ratio.

De igual modo, a dialética da modemidade, que procura impregnar o direito penal, não pode seolvidar queo bemjurídico desempenha papel central na estrutura do delito, justificando e delimitando o conteúdo da norma.

Namesmalinha, ostemposatuaisnão viabi lizamqual quer discurso penal que proponha a flexibilização de garantias individuais a um determinado grupo de pessoas, em especial de garantias relacionadas a liberdade do cidadão, como se fosse justificável perder de vista o marco-político criminal recente

51 BOBBIO - ao prefaciar a obra de Ferrajoli “Direito e Razão Teoria do Garantismo Penal", São Paulo, RT, 2002.

Revista Esmat, Pal mas, Ano 5, № 5, pag. 191 a 217 - jan/jun 2013 
que vinha impondo uma constante e paulatina humanização do direito penal.

Encerra-se, frisando que a ideologia do inimigo, assentada em premissas epistemológicas questionávés, não ganha eco quando confrontada com o conteúdo do texto constitucional brasileiro, primeiro porque a Constituição brasileira exige que a matriz penal e processual penal do país seja de cunho antropocêntrico, segundo porque esta matriz antropocêntrica moldou a Justiça em uma escala entre sólida e profusa e a uniu estritamente aos cidadãos. Ela dotou a institui ção daJ ustiça com todos os meios que ela necessita para funcionar em uma sociedade moderna, ela concedeu à J ustiça espaço para prosseguir no desenvolvimento social e the confiou a proteção daquel es di reitos sem os quais os seres humanos não sobreviveriam em um mundo social izado. ${ }^{52}$

\section{REFERÊNCIAS BIBLIOGRÁFICAS}

ADORNO, T.W \& HORKHEIMER, M. Dialética do E sclarecimento: fragmentos filosóficos. Trad. Guido Antonio deAlmeida. Rio deJ aneiro: J orge Zahar, 1997.

AMARAL, Cláudio Prado do. Bases Teóricas da Ciência Penal Contemporânea: dogmática, missão do direito penal e

52 HASSEMER, Winfried, "Direito Penal Libertário" trad. Regina Greve, Belo Horizonte: Del Rey, 2007, P. 23.

Revista Esmat, Pal mas, Ano 5, no 5, pag. 191 a 217 - jan/jun 2013

212 
política criminal na sociedade de risco. São Paulo: IBCCRIM, 2007 (Monografias IBCCRIM; 44).

ARANA, Raul Pariona. El derecho penal "moderno" sobre la necesaria legitimidad de la intervenciones penales. Revista Brasileira de Ciências C riminais, n.68. São Paulo: Revista dos Tribunais, set- out. 2007, p. 315-371.

BARATTA. Integracion-prevención: uma nueva fundamentación dela pena dentro delateoriasistêmica. Doctrina penal: teoria y prática em lãs ciências penales, año 8, númeors 29 a 32. Buenos Aires: Ediciones Depal ma, 1985.

BECK, Francis Rafael. Perspectivas de controle ao crime organizado e critica à flexibilização das garantias. São Paulo: IBCCRIM, 2004.

BECK, Ülrich. A Reinvenção da Política. Em: Giddens, A., Beck, U. \& Lash, S.: (Orgs.). Modernização Reflexiva: política, tradição e estética na ordem social moderna. (p. 211-212). São Paulo: UNESP.

BECK, Ülrich. Sociedade del riesgo: hacia uma nueva modernidad (Título original Risikogesellschaft. Auf dem Weg in eine andere Moderne, 1986). Trad. J orge Navarro, Daniel Jimenez e Maria Rosa Borras. Barcelona: Paidós Ibérica, 1998. 
BENEDETTI, Juliana Cardoso. Raízes sociológicas do funcional ismo penal. R evista B rasileir a de C iências C riminais, n.73. São Paulo: Revista dos Tribunais, jul. - ago. 2008, p. 9-47.

BOBBIO - ao prefaciar a obra de Ferrajoli "Direito e Razão Teoria do Garantismo Penal", São Paulo, RT, 2002.

BOZZA, Fábio da Silva. Análise critica da prevenção geral positiva no funcional ismo sistêmico de Günther J acobs. R evista B rasileira de C iências C riminais, n.70. São Paulo: Revista dos Tribunais, set. - out 2007, p. 41-69.

BUSATO, Paulo César. Quem é o inimigo, quem é você?. Revista Brasileira de Ciências Criminais, n.66. São Paulo: Revista dos Tribunais, mai - jun. 2007, p. 112-139.

CASTIEL, L. D. (2001) A Centralidade da Regulação na Sociedade de Risco. Fio Cruz. Disponível em <http://www. ensp.fiocruz.br/projetos/esterisco/suor6.htm>. Acesso em: 07/01/09.

DÍEZ RIPOLLÉS, José Luis: De la sociedad del riesgo a la seguridad ciudadana: um debate desenfocado, em Revista Electrónica de Ciencia Penal y Criminología, 09/01/2009.

FERRAJ OLI, Luigi. Direito e razão: teoria do garantismo penal. São Paulo : Editora Revista dos Tribunais, 2002.

HASSEMER, Winfried. Direito Penal Libertário. Trad. Regina Greve, Belo Horizonte: Del Rey, 2007.

HOY OS, Gustavo Balmaceda. Consideraciones críticas sobre El derecho penal moderno y su legitimidad. R evista Brasileira 
de Ciências C riminais, n.65. São Paulo: Revista dos Tribunais, mar.-abr.2007.

JACOBS, Günther. Derecho penal del enemigo. Tradução de Cancio Meliá.Madrid: Civitas, 2003.

JACOBS, Günther. Derecho penal: parte general. 2. ed. Tradução de Joaquim Cuello Contreras y J ose Luis Serrano Gonzáles de Murrillo. Madrid: Marcial Pons, 1997.

JACOBS, Günther. Sobre la teoria de la pena. Traducción de Manuel Cancio Meliá. Centro de Investigaciones de Derecho Penal y Filosofia del Derecho de La Universidad Externado de Colombia, 2002, p. 18.

JACOBS, Günther. Sociedade, norma e pessoa: teoria de um direito penal funcional. Barueri: Manole, 2003.

JACOBS, Günther.Criminalización en El estádio previo de la lesión de um bem jurídico. In: Estudios de derecho penal. Madrid: Civitas, 1997.

MACHADO, Marta Rodriguez de Assis. Sociedade do Risco e Direito Penal: uma avaliação de novas tendências político-criminais. São Paulo: IBCCRIM, 2005. (Monografias/ IBCCRIM; 34).

MACHADO, Marta Rodriguez de Assis. Sociedade do R isco e Direito Penal: uma avaliação de novas tendências políticocriminais. São Paulo : IBCCRIM, 2005 (Monografias/IBCCRIM; 34).

MORAES, Vinicius Borges de. Concepções jusfilosóficas do

Revista Esmat, Pal mas, Ano 5, № 5, pag. 191 a 217 - jan/jun 2013 
direito penal do inimigo: uma analise sobre os fundamentos da teoria de Günther Jacobs.Revista Brasileira de Ciências Criminais, n.74. São Paulo: Revista dos Tribunais, set-out. 2008, p.10-34.

MUÑOZ CONDE, Francisco. Direito Penal e controle social. Trad. Cintia Toledo Miranda Chaves. Rio de J aneiro: Forense, 2005.

MUÑOZ CONDE, Francisco: Introdución al derecho penal. Montevideo-BuenosAires: B deF, 2003.

NAUCK, Wolfgang, HASSEMER, Winfried, LÜDERSSEN, Klaus. Principales problemas dela prevención $\mathrm{G}$ eneral. Trad. Gustavo Eduardo Aboso. Montevideo - Buenos Aires: B de F, 2004.

NAVARRO, Marli B. M. de A. \& Cardoso, Telma A. de O. (2005). Percepção de Risco e cognição: reflexão sobre a sociedade de risco. Ciências \& Cognição; Ano 02, Vol.06, nov/2005.

NEUMANN. Ulfrid. Direito Penal do Inimigo Tradução Antonio Martin Revista Brasileira de Ciências Criminais, n.68. São Paulo: Revista dos Tribunais, nov - dez. 2007, p. 156-177.

NEUMANN. Ulfrid. Direito Penal do Inimigo. TraduçãoAntonio Martin. Revista Brasileira de Ciências Criminais, n.69. São Paulo: Revista dos Tribunais, nov-dez. 2007, p. 156-177.

NÚÑEZ PAZ, Miguel Ángel. Dogmática penal y política criminal frente a la reforma penal. Revista Brasileira de Ciências Criminais, n.61. São Paulo: Revista dos Tribunais, 
jul. - ago. 2006.

PEÑARENDA RAMOS, Enrique et al. Um novo sistema do direito penal. Considerações sobre a teoria de Günther Jacobs. Trad. André Luís Callegari e Nereu J osé Giacomolli. Barueri: Manole, 2003.

PRITTWITZ, Cornelius. O direito penal entre o direito penal do risco e o direito penal do inimigo: tendências atuais entre direito penal e política criminal. R evista B rasileira de C iências Criminais, n.47. São Paulo: Revista dos Tribunais, mar.abr.2004, p. 31-45.

SANTANA VEGA, Dulce Maria. La protección penal de los biens jurídicos colectivos. Madrid: Dikinson, 2000, p. 103.

TAVARES, Juarez. Teoria do Injusto Penal. 2 a edição. rev. e ampl. Belo Horizonte: Del Rey 2002.

ZAFFARONI, Eugenio Raul. EI enemigo en EI derecho penal. 1aed., 1a reimp. BuenosAires: Ediar, 2007. 